\title{
Gluconobacter oxydans Knockout Collection Finds Improved Rare Earth Element Extraction
}

\author{
Alexa M. Schmitz ${ }^{1}$, Brooke Pian ${ }^{1}$, Sean Medin ${ }^{1}$, Matthew C. Reid ${ }^{3}$, Mingming Wu ${ }^{1}$, Esteban Gazel ${ }^{2}$, Buz \\ Barstow $^{1 \dagger}$ \\ ${ }^{1}$ Department of Biological and Environmental Engineering, Cornell University, Ithaca, NY 14853, USA \\ ${ }^{2}$ Department of Earth and Atmospheric Sciences, Cornell University, Ithaca, NY 14853, USA \\ ${ }^{3}$ School of Civil and Environmental Engineering, Cornell University, Ithaca, NY 14853, USA \\ ${ }^{\dagger}$ Corresponding author: \\ Buz Barstow, 228 Riley-Robb Hall, Cornell University, Ithaca, NY 14853; bmb35@cornell.edu
}

\begin{abstract}
Rare earth elements (REE) are critical components of our technological society and essential for renewable energy technologies. Traditional thermochemical processes to extract REE from mineral ores or recycled materials are costly and environmentally harmful ${ }^{1}$, and thus more sustainable extraction methods require exploration. Bioleaching offers a promising alternative to conventional REE extraction ${ }^{2-4}$, and is already used to extract $5 \%$ of the world's gold, and $\approx 15 \%$ of the world's copper supply ${ }^{5,6}$. However, the performance of REE bioleaching lags far behind thermochemical processe ${ }^{2,7-9}$. Despite this, to the best of our knowledge no genetic engineering strategies have yet been used to enhance REE bioleaching, and little is known of the genetics that confer this capability. Here we build a whole genome knockout collection for Gluconobacter oxydans B58, one of the most promising organisms for REE bioleaching ${ }^{10}$, and use it to comprehensively characterize the genomics of REE bioleaching. In total, we find 304 genes that notably alter production of G. oxydans' acidic biolixiviant, including 165 that hold up under statistical comparison with wild-type. The two most impactful groups of genes involved in REE bioleaching have opposing influences on acid production and REE bioleaching. Disruption of genes underlying synthesis of the cofactor pyrroloquinoline quinone (PQQ) and the PQQ-dependent membrane-bound glucose dehydrogenase all but eliminates bioleaching. In contrast, disruption of the phosphate-specific transport system accelerates acid production and enhances bioleaching. We identified 6 disruption mutants, that increase bioleaching by at least $11 \%$. Most significantly, disruption of $p s t C$, encoding part of the phosphate -specific transporter, pstSCAB, enhances bioleaching by $18 \%$. Taken together, these results give a comprehensive roadmap for engineering multiple sites in the genome of $G$. oxydans to further increase its bioleaching efficiency.
\end{abstract}

\section{Introduction}

Rare earth elements (REE) are essential for the manufacturing of modern electronics ${ }^{11-13}$, and sustainable energy technologies including electric motors and wind turbine generators ${ }^{14}$; solid state lighting ${ }^{15}$; battery 
$\operatorname{anodes}^{16}$; high-temperature superconductors ${ }^{17}$; and high-strength lightweight alloys ${ }^{18,19}$. All of these applications place increasing demands on the global REE supply chain ${ }^{20}$. As the world demand for sustainable energy grows ${ }^{21}$, finding a reliable and sustainable source of REE is critical.

Current methods for refining REE often involve harsh chemicals, high temperatures, high pressures and generate a considerable amount of toxic waste ${ }^{22}$. These processes give sustainable energy technologies reliant on REE a high environmental and carbon footprint. As a consequence, due to its high environmental standards, the United States has no capacity to produce purified REE ${ }^{23,24}$.

There is growing interest in biological methods to supplement, if not completely replace traditional REE extraction and purification methods $\mathrm{s}^{2,825-27}$. Biological extraction (bioleaching) is already used to extract $5 \%$ of the world's gold ${ }^{5,6}$, and $\approx 15 \%$ of the world's copper supply ${ }^{5,6}$ (in fact, Cu biomining in Chile alone accounts for $10 \%$ of the world's Cu supply ${ }^{28,29}$ ).

The performance of REE-bioleaching lags behind thermochemical processes. For example, while thermochemical methods have $89-98 \%$ REE extraction efficiency from monazite ore ${ }^{7,30}$, Aspergillus species can only achieve $\approx 3-5 \%^{2}$. The acid-producing microbe Gluconobacter oxydans B58 can recover $\approx 50 \%$ of REE from FCC catalysts ${ }^{10}$. However, techno-economic analysis indicates that even this extraction efficiency is still not high enough for commercial application ${ }^{8}$.

Recent efforts to improve bioleaching have focused exclusively on process optimization ${ }^{4}$. To our knowledge, no genetic approaches have yet been taken for any bioleaching microbe ${ }^{31}$. With recent advances in tools for reading and writing genomes, genetic engineering is an attractive solution for enhancing bioleaching. However, applying these tools to non-model microorganisms like $G$. oxydans can be a significant challenge ${ }^{19}$. And while there have been some promising advances for editing $G$. oxydans ' genome $^{32-37}$, we do not yet know where to edit.

In the presence of glucose, G. oxydans secretes a biolixiviant rich in gluconic acid ${ }^{10}$. This is produced by periplasmic glucose oxidation by the pyrroloquinoline quinone (PQQ)-dependent membrane-bound glucose dehydrogenase $(\mathrm{mGDH})^{38}$. The final $\mathrm{pH}$ of the biolixiviant is a major factor in REE bioleaching ${ }^{10}$. But, gluconic acid alone fails to explain bioleaching by G. oxydans: pure gluconic acid is far less effective at bioleaching than the biolixiviant produced by G. oxydans ${ }^{10}$. This means that even the most successful efforts to up-regulate mGDH activity and gluconic acid production are unlikely to take full advantage of $G$. oxydans' biolixiviant production capabilities.

To characterize the genome of $G$. oxydans and identify a comprehensive set of genes underlying its bioleaching capabilities, we built a carefully curated whole-genome knockout collection of single-gene transposon disruption mutants using Knockout Sudoku ${ }^{39,40}$ (Fig. 1). Final pH of the biolixiviant is a good predictor for bioleaching efficiency ${ }^{10}$, thus we used acidification as a proxy for bioleaching potential and have thoroughly screened the collection to identify mutants that differ in their ability to produce acidic biolixiviant (Figs. 2 and 3). Finally, we demonstrate that a single gene disruption - only one of several potential enhancement strategies - can already significantly improve G. oxydans' bioleaching capabilities (Fig. 4). 


\section{Results and Discussion}

\section{Development of a Knockout Collection for G. oxydans Covering 2,733 Genes}

We built a saturating coverage transposon insertion mutant collection for G. oxydans B58 and catalogued and condensed it with the Knockout Sudoku combinatorial pooling method ${ }^{39,40}$ (Fig. 1). We sequenced the G. oxydans B58 genome and identified 3,283 open reading frames (Fig. 1A; Table S1; Materials and Methods). Following the recommendation of Monte Carlo simulations, we collected 49,256 transposon insertion mutants (the progenitor collection; PC) to ensure saturating coverage of the G. oxydans B58 genome (Fig. 1B; Materials and Methods).

Progenitor collection sequencing results indicate that we were able to generate at least one disruption mutant for almost every non-essential gene in the $G$. oxydans genome. In total, we identified disruption strains for 2,733 genes out of the 3,283 genes in the G. oxydans B58 genome. Since every predicted gene contains at least seven AT or TA transposon insertion sites (Table S1), the remaining 550 non-disrupted genes are likely to be essential. A Fisher's Exact Test for gene ontology (GO) enrichment representing 268 of the non-disrupted genes demonstrated significant enrichment $(p<0.05)$ in several essential ontologies, with the greatest enrichment in those relating to the ribosome and translation (Fig. 1C and Table S2A).

The progenitor collection catalog was used to create a condensed G. oxydans disruption collection with at least one representative per non-essential gene. 47 progenitor strains were verified by Sanger sequencing prior to condensing, of which 43 (92\%) were confirmed to have the predicted transposon coordinate (Table S3A). We selected one mutant for all 2,733 disrupted genes, a second mutant for 2,354 genes, and a third mutant for 50 genes where mutant location information was poor. All mutants were struck out for single colonies, and 2-10 colonies per mutant were picked, depending on the predicted number of crosscontaminating disruption strains in the originating well. This condensed collection contains 17,706 mutants in 185 96-well plates (Table S4).

The condensed collection catalog was validated by a second round of combinatorial pooling and sequencing. Of the 17,706 wells in the condensed collection, we were able to confirm the identity for 15,257 (Table S4). We confirmed 25 of these wells by Sanger sequencing, and 100\% have the predicted transposon coordinate (Table S3B). Among these wells, we were able to verify the identity and location of 4,419 independent transposon insertion sites, representing a disruption mutant for 2,556 unique genes (Fig. 1D). 1,587 genes are represented by more than one disruption, and 3,317 of all disruptions occur in the first half of the gene (Table S4).

\section{Genome-wide Screening Discovers 165 Genes Significantly Linked to Acid Production}

We screened the new G. oxydans B58 whole genome knockout collection for disruption mutants with differential acidification capability (Fig. 2). We used the colorimetric $\mathrm{pH}$ sensitive dye Thymol Blue (TB) to screen for changes in final biolixiviant $\mathrm{pH}$ (Figs. 2A and S1), and Bromophenol Blue (BPB) to screen for changes in rate of acidification (Fig. 2B).

In total, we noted 304 genes that apparently controlled acidification (Fig. 2C and Table S5). The TB screen discovered 282 genes whose disruption leads to a differential change in biolixiviant acidity (Fig. 2C and Table S5). 47 mutants produced a more acidic biolixiviant, while 235 produced a less acidic one (Fig. 2C and Table S5). The BPB screen identified 82 gene disruptions with differential rate of acidification: 49 
with a faster rate, and 33 with a slower rate. 60 mutants were identified by both screens (Fig. 2C and Table S5).

Overall, we identified 165 genes that significantly $(p<0.05)$ changed the final biolixiviant $\mathrm{pH}$, rate of acidification, or both, but did not change the growth rate (Fig. 2C and Table S6). We re-arrayed disruption strains with differential acidification into new 96-well plates alongside proxy wild-type (pWT) strains (Materials and Methods) that have a transposon insertion in an intergenic region and show non-differential growth or biolixiviant production (Fig. S2). The new collection was re-assayed with the TB and BPB assays and the strength and significance of each result was determined by comparison with pWT through a Bonferroni-corrected $t$-test (Materials and Methods). Mutants that cause the 25 largest reductions, and 50 largest increases in endpoint acidity yet do not affect growth rate are shown in Fig. 2D. A full set of mutants that cause significant changes in acidification are listed in Table S6.

31 mutants that cause significant changes in acidification rate without changing growth rate are shown in Fig. 2E and Table S6F. However, 14 of the faster strains, including $\delta G O \_868$, a disruption of a LacI type transcriptional repressor which was the fastest strain, produced a less acidic biolixiviant than the wild-type, indicating that targeting these genes for engineering a faster acidifier would likely be at the expense of a more acidic biolixiviant. None of the strains with a faster rate of acidification also created a more acidic biolixiviant. This result suggests that multiple genetic engineering interventions will be needed to construct a strain of $G$. oxydans that simultaneously produces a more acidic biolixiviant than the wild-type at a faster initial rate.

\section{Phosphate Transport and PQQ Synthesis are the Biggest Controllers of Acidification}

We used a Fisher's Exact Test to determine which biological processes, metabolic functions, and cellular components are enriched among the gene disruptions that significantly change biolixiviant acidification (Fig. 3). Among the disrupted genes that led to a stronger acidity, the most significant enrichment for all three GO categories involves the phosphate-specific transport system, represented by $p s t A, p s t B, p s t C$, pst $S$, and $p h o R$ (Fig. 3A). Other enriched ontologies include those related to phosphate signaling and binding.

Among the disrupted genes that led to a weaker acidity, several enriched GO are related to the synthesis or use of the redox cofactor, PQQ, represented by $p q q B, p q q C, p q q E, t l d D$, and $m g d h$ (Fig. 3B). Other enriched ontologies include those related to carbohydrate metabolism.

Acidification rate is controlled by carbohydrate metabolism and respiration. Disruptions in the pentose phosphate pathway increase acidification rate (Fig. 3C). Meanwhile, disruptions of the electron transport pathway components are the most significantly enriched group of mutants that decrease acidification rate (Fig. 3D).

\section{Single Gene Knockout Mutants Can Significantly Change REE Bioleaching}

\section{Validation of Dye Assays by Direct pH Measurements}

We selected 22 strains from those with greatest increase or decrease in acidification (Figs. 2D and $\mathbf{E}$ ) for further testing. Dye $\mathrm{pH}$ measurements were validated by direct $\mathrm{pH}$ measurements. 11 of the 13 strains that produced significantly lower acidity biolixiviant in TB assays did the same in direct pH measurements (Fig. 4A). The most acidic biolixiviant was produced by a disruption in the phosphate transport gene, $\delta p s t C$ at 
$\mathrm{pH}$ 2.09. In fact, 4 of the 11 mutant strains that produced a more acidic biolixiviant were disrupted in genes involved in the phosphate-specific transport system ( $\delta p s t A, \delta p s t B, \delta p s t C$, and $\delta p s t S)$.

Additional disruptions that led to a more acidic biolixiviant included those in a hypothetical protein with no similarity to anything previously characterized ( $\left.\delta G O_{-} \_1415\right)$; a gamma-glutamyltranspeptidase ( $\left.\delta g g t 1\right)$; a periplasmic chaperone ( $\delta$ sur $A)$; an HTH-type transcriptional regulator ( $\delta$ pet $P$ ); a two-component system sensor histidine kinase $(\delta y k o H)$; a Pyridoxal 5-phosphate (PLP)-dependent ornithine decarboxylase ( speC); and a TPR domain protein that is a putative component of the TonB iron uptake system ( $\delta$ ton $B)$.

9 of the tested strains produced biolixiviant significantly higher in $\mathrm{pH}$ than $\mathrm{pWT}$ (Fig. 4B). The most alkaline biolixiviant was produced by a disruption in the PQQ synthesis system, $\delta p q q C$, at $\mathrm{pH} 4.71$. While $\delta p q q C$ produced very little acid, this is below the $\mathrm{pH}$ of glucose in media alone, indicating that some bacterial acidification still occurred. In fact, 3 of the 9 mutants that produce reduced acidity biolixiviant either synthesize PQQ ( $\delta p q q C$ and $\delta t l d D)$, or use it as a cofactor $(\delta m g d h)$.

Additional disruptions that led to a more alkaline biolixiviant than pWT include a Fructose-bisphosphate aldolase class II ( $\left.\delta G O \_3252\right)$; a GTP and nucleic acid binding protein $(\delta y c h F)$; a lipid A biosynthesis protein $(\delta h t r B)$; a peptide chain release factor $(\delta h e m K)$; the LacI type transcriptional repressor that increases initial acidification rate $\left(\delta G O \_868\right)$; and the second component of a proteolytic complex with TldD $(\delta t l d E)$.

\section{Disrupting the Phosphate Transport System Significantly Increases Bioleaching}

We tested if 10 of the mutants that produced a more acidic biolixiviant could bioleach REE from retorted phosphor powder (RPP) from spent fluorescent lightbulbs more efficiently than pWT (Fig. 4C). For each mutant, the elemental composition of REE leachate was similar to that previously reported ${ }^{10}$. Six of these mutants significantly increased bioleaching. Two of the better bioleaching mutants disrupted the pst phosphate transport system ( $\delta p s t C$ and $\delta p s t B)$. Overall, we found that bioleaching efficiency correlates with biolixiviant $\mathrm{pH}$, as expected (Fig. 4E).

The $\delta p s t C$ mutant produced the most acidic biolixivant and extracted the most REE from RPP: 5.5\% total extraction efficiency as compared with pWT's $4.7 \%$. Put another way, $\delta p s t C$ removed $18 \%$ more REE from RPP than $\mathrm{pWT}$. This increase in REE extraction remains significant even after adjusting the $\alpha$ to account for the possibility of a difference due to chance alone (Bonferonni correction, see Materials and Methods). Without the adjustment, six of the better acidifiers were also better bioleachers than pWT (Fig. 4C). The remaining better bioleachers increased REE extraction by between $11 \%(\delta o d c)$ and $18 \%(\delta g g t l)$ (Fig. 4C).

We speculate that disrupting phosphate transport and signaling de-represses acid production in $G$. oxydans. Six of the disruption strains that resulted in a lower biolixiviant $\mathrm{pH}(\delta p s t C, \delta p s t B, \delta g g t 1, \delta p s t A, \delta p s t S$, and $\delta y k o H)$, including three that increased bioleaching ( $\delta p s t C, \delta p s t B, \delta g g t 1)$, along with many more identified by acidification high-throughput assays (e.g., $\delta p h o R, \delta e n v Z)$, are involved in phosphate transport, sensing and signaling.

In its natural environment, $G$. oxydans produces biolixiviants to liberate phosphate from minerals, not metals ${ }^{41-43}$. Under phosphate-limiting conditions, the PstSCAB phosphate transporter will activate the histidine kinase, PhoR, which in turn phosphorylates the transcription factor PhoB, and activates the pho regulon, enabling phosphate solubilization and uptake ${ }^{44}$. Under sufficient phosphate conditions, PhoB is deactivated by PhoR, which in turn inhibits expression of genes involved in the phosphate-starvation 
response. We speculate that by disrupting pstSCAB or PhoR, we prevent $G$. oxydans from sensing when there is adequate phosphate in its environment and when to stop producing biolixiviants.

\section{Disrupting $\boldsymbol{m g d h}$ and PQQ Synthesis Genes Significantly Decreases Bioleaching}

We also tested REE extraction by 4 mutants that produce a less acidic biolixiviant than pWT, and all were worse bioleachers than pWT (Figs. 4C and D). Unsurprisingly, $\delta m g d h$ mutant was the worst bioleacher of all tested, considering its lack of gluconic-acid production ${ }^{38}$. $\delta m g d h$ reduced bioleaching by $97 \%$. Disruption mutants that knocked out synthesis of mGDH's essential redox cofactor, PQQ, also produced significant reductions in biolixiviant acidity. $\delta p q q C$ reduced bioleaching by $\approx 94 \%$. While bioleaching by $\delta m g d h$ and $\delta p q q C$ was negligible compared to $\mathrm{pWT}$, they were able to bioleach a statistically significant amount of REE compared to glucose alone. This indicates, as previously speculated ${ }^{10}$, that a bioleaching mechanism independent of mGDH exists in G. oxydans (Fig. 4D).

Disruption mutants in $t l d D$ and $t l d E$ were also much worse at bioleaching than pWT. $\delta$ tldD reduces bioleaching by $92 \%$, while $\delta t l d E$ reduces it by $63 \%$ (Fig. 4C). We speculate that TldD and TldE contribute to the supply of the PQQ cofactor to mGDH. $\delta$ tldD strongly attenuates acid production (Fig. 4B), and the gene has already been implicated in PQQ synthesis in G. oxydans $621 \mathrm{H}^{45}$. In E. coli, TldD and TldE form a two-component protease for the final cleavage step in the processing of the peptide antibiotic, Microcin $\mathrm{B} 17^{46}$. In a similar manner, PqqF and PqqG from Methylorubrum extorquens form a protease that rapidly cleaves PqqA, the peptide precursor to PQQ ${ }^{47}$. We speculate that TldD in G. oxydans plays the same role as PqqF from M. extorquens, while TldE plays the same role as PqqG. Deletion of $p q q F$ in $M$. extorquens completely inhibits cleavage of PqqA, while we find that disruption of $t l d D$ in $G$. oxydans reduces REE bioleaching by $92 \%$. Moreover, deletion of $p q q G$ in $M$. extorquens only reduces PqqA cleavage by $50 \%{ }^{47}$, while disruption of $t l d E$ only reduces REE bioleaching by $63 \%$. These parallels strongly indicate a novel role for TldE in the biosynthesis of PQQ in G. oxydans.

\section{Conclusions}

Bioleaching has the potential to revolutionize the environmental impact of REE production, and dramatically increase access to these critical ingredients for sustainable energy technology. But, making REE bioleaching cost competitive with thermochemical methods will require increasing both the rate and completeness (overall efficiency) of REE extraction. This work gives us a roadmap for improving bioleaching by genetic engineering.

By constructing a whole genome knockout collection for G. oxydans, one of the most promising organisms for REE bioleaching, we are able to characterize the genetics of this process with high sensitivity and high completeness. In total we have identified 165 gene disruption mutants that significantly change the acidity of its biolixiviant, rate of production, or both. The regulatory elements of each of these genes represents a dial that can be turned to improve bioleaching.

As well as producing gluconic acid, $G$. oxydans can be used in the production of industrially important products including 2,5-Diketogluconic Acid, a precursor of Vitamin $\mathrm{C}^{48}$; 5-Ketogluconic Acid, a precursor of $\mathrm{L}(+)$-tartaric acid used in the production of food and pharmaceuticals ${ }^{48}$; vinegar; sorbitol; and dihydroxyacetone ${ }^{48}$. The G. oxydans knockout collection will allow characterization of the production of these metabolites and improvement of their production. 
REE bioleaching by G. oxydans is predominantly controlled by two well-characterized systems: phosphate signaling and glucose oxidation that is supported by production of the redox cofactor PQQ. Interrupting phosphate signaling control of biolixiviant production by disrupting a single gene (pstC) can increase REE extraction by $18 \%$. Disrupting the supply of the PQQ cofactor to the membrane bound glucose dehydrogenase reduces REE extraction by up to $92 \%$.

Comprehensive screening of the G. oxydans genome also revealed completely new targets that contribute to REE bioleaching. For example, disrupting $G O_{-} 1415$, encoding a protein of unknown function, increases REE bioleaching by $15 \%$. Additionally, our results highlight the potential for a previously uncharacterized role of TldE in PQQ synthesis. Several periplasmic dehydrogenases in G. oxydans depend on PQQ for their function $^{49}$, and in the case of the D-sorbitol dehydrogenase, mSLDH, over-expression of the $p q q$ synthase genes and $t l d D$ enhances conversion of N-2-hydroxyethyl-glucamine into 6-(N-hydroxyethyl)-amino-6deoxy-L-sorbofuranose (6NSL), a precursor to the diabetes drug, Miglitol ${ }^{50,51}$. The discovery of the potential contribution of TldE to PQQ biosynthesis may allow for exceptional enhancement of the cofactor production through the additional over-expression of this gene, and a consequent uptick in dehydrogenase activity. PQQ is an essential cofactor important for several other industrial applications of G. oxydans, including production of L-sorbose ${ }^{52}$ and 5-keto-D-gluconate ${ }^{53}$. Furthermore, PQQ alone has many applications across many biological processes from plant protection to neuron regeneration ${ }^{54}$.

Our results are the first ever demonstrating improvement of bioleaching through genetic engineering. Furthermore, the creation of a whole-genome knockout collection in G. oxydans will facilitate its use as a model species for further studies in REE bioleaching and other industrially important applications of similar acetic acid bacteria. The findings of the two major systems contributing to acidification in G. oxydans suggest the first steps in the roadmap for greatly improving bioleaching: take the brakes off regulation of acid production by disabling the phosphate-specific transport system, while over-expressing $m g d h$ along with the expanded synthesis pathway for its cofactor PQQ. 


\section{Materials and Methods}

\section{Gluconobacter oxydans B58 Genome Sequencing}

Gluconobacter oxydans strain NRRL B-58 (GoB58) was obtained from the American Type Culture Collection (ATTC), Manassas, VA. In all experiments, GoB58 was cultured in yeast peptone mannitol media (YPM; $5 \mathrm{~g} \mathrm{~L}^{-1}$ yeast extract, $3 \mathrm{~g} \mathrm{~L}^{-1}$ peptone, $25 \mathrm{~g} \mathrm{~L}^{-1}$ mannitol), with or without antibiotic, as specified.

Genomic DNA was extracted from saturated culture using a Quick-DNA Miniprep kit from Zymo Research (Part number D3024, Irvine, CA). Genomic DNA library was prepared and sequenced using a TruSeq DNA PCR-Free Library Prep Kit (Illumina, San Diego, CA).

The prepared library was sequenced on a MiSeq Nano (Illumina, San Diego, CA, USA) with a 500 bp kit at the Cornell University Institute of Biotechnology (Ithaca, NY, USA). Resulting paired end reads were trimmed using Trimmomatic ${ }^{55}$ and assembled with SPAdes using k-mer sizes 21, 33, 55, 77, 99, and 127, and auto coverage cutoff ${ }^{56}$. Assembly quality was checked with QUAST ${ }^{57}$ and genome completeness was verified with $\mathrm{BUSCO}^{58}$ using the proteobacteria_odb9 database for comparison. The resulting 62 contigs were annotated online using RAST (https://rast.nmpdr.org) ${ }^{59-61}$.

\section{Gene Ontology Enrichment}

DIAMOND $^{62}$ was used to assign annotated protein models with a closest blast hit using the the uniref90 database, an $E$-value threshold of $10^{-10}$, and a block size of 10 . InterProScan ${ }^{63}$ (version 5.50-84.0) was used to assign family and domain information to protein models.

Output from both of these searches was used to assign gene ontologies with BLAST2GO ${ }^{64}$. Gene set enrichment analysis was done with BioConductor topGO package ${ }^{65}$, using the default weight algorithm, the TopGO Fisher test, with a $p$-value threshold of 0.05 .

\section{Mating for Transposon Insertional Mutagenesis}

The transposon insertion plasmid, pMiniHimarFRT ${ }^{39}$ was delivered to GoB58 by conjugation with E. coli WM3064. E. coli WM3064 transformed with pMiniHimarFRT was grown overnight to saturation in $50 \mathrm{~mL}$ LB (10 $\mathrm{g} \mathrm{L}^{-1}$ tryptone, $5 \mathrm{~g} \mathrm{~L}^{-1}$ yeast extract, and $\left.10 \mathrm{~g} \mathrm{~L}^{-1} \mathrm{NaCl}\right)$ supplemented with $50 \mu \mathrm{g} \mathrm{mL}^{-1}$ kanamycin (kan) and $90 \mu \mathrm{M}$ diaminopimelic acid (DAP), rinsed once with $50 \mathrm{~mL} \mathrm{LB}$, then re-suspended in $20 \mathrm{~mL}$ YPM.

GoB58 was grown for approximately 24 hours in YPM, then back-diluted to an optical density (OD) of 0.05 in $750 \mathrm{~mL}$ YPM and incubated at $30^{\circ} \mathrm{C}$ for two doublings until the OD reached 0.2. GoB58 culture was distributed into $1350 \mathrm{~mL}$ conical tubes, to which rinsed and re-suspended WM3064 was added at a ratio of 1:1 by density (approximately $1 \mathrm{~mL} \mathrm{WM3064} \mathrm{to} 50 \mathrm{~mL} \mathrm{B58)}$ ). Bacteria were mixed by inversion then spun down at $1900 \mathrm{~g}$ for 5 minutes. Supernatant was poured off, and the mixture was resuspended in the remaining liquid $(\approx 0.5 \mathrm{~mL})$, pipetted onto a YPM plate in 5 spots of $0.1 \mathrm{~mL}$, and allowed to dry on the bench under a flame.

Mating plates were incubated at $30^{\circ} \mathrm{C}$ for 24 hours. Mating spots were collected by adding $4 \mathrm{~mL}$ YPM to a plate, scraping the spots into the liquid, then suspending by pipetting up and down several times. 
Suspended cells were collected from each plate, and the suspension was plated onto YPM agar with 100 $\mu \mathrm{g} \mathrm{mL} \mathrm{m}^{-1}$ kanamycin at $100 \mu \mathrm{L}$ per plate.

After 3 days of incubation at $30^{\circ} \mathrm{C}$, colonies were picked into 96-well microplates using a CP7200 colony picking robot (Norgren Systems, Ronceverte WV, USA). Each well contained $150 \mu \mathrm{L}$ YPM with $100 \mu \mathrm{g}$ $\mathrm{mL}^{-1}$ kanamycin. For all high-throughput experiments, GoB58 was grown in polypropylene microplates sealed with a sterile porous membrane (Aeraseal, Catalog Number BS-25, Excel Scientific) and incubated at $30{ }^{\circ} \mathrm{C}$ shaking at $800 \mathrm{rpm}$. Isolated disruption strains were grown for three days to allow nearly all wells to reach saturation. Wells B2 and E7 of each plate were reserved as no-bacteria controls.

A Monte Carlo numerical simulation (collectionme ${ }^{39}$ ) was used to approximate how many insertions would need to occur before a mutant is found representing a knockout of each gene in the genome, which demonstrated that approximately 55,000 mutants would need to be generated and selected to identify mutants in at least $99 \%$ of all GoB58 genes (Fig. 1B).

In total 18 matings were required to recover and pick a progenitor collection of 49,256 disruption strains into 525 microplates over the course of about two months. Microplates with saturated wells were maintained at $4^{\circ} \mathrm{C}$ for up to 3 weeks and incubated an extra night at $30^{\circ} \mathrm{C}$ before pooling.

Combinatorial pooling was done in three batches. The 525 plates were virtually arranged in a 20 by 27 grid, and combinatorial pooling, cryopreservation, pool amplicon library generation, and sequencing were all done as previously described ${ }^{39,40}$.

\section{Curation of a whole-genome knockout collection}

Sequencing data for the progenitor collection was processed into a progenitor collection catalog using the KOSUDOKU suite of algorithms ${ }^{39,40}$. To create a condensed collection, a disruption strain was chosen for each of the 2,733 disrupted genes available in the progenitor collection, first prioritizing close proximity to the translation start, then the total probability of the proposed progenitor collection address. A second strain was chosen from the remaining strains for each gene that had another available. For 50 genes, both disruption strains selected were ambiguously located, and thus a third strain was selected from the remaining collection.

In total, 5,137 disruption strains were isolated and struck-out for single colonies. Many progenitor wells were predicted to have more than one possible strain per well, so for each strain, the number of colonies isolated was two times the predicted number of strains in the progenitor well, up to ten. The condensed collection, which amounted to 17,706 wells, was pooled, sequenced, and validated as previously described $^{39,40}$. Unknown disruption strains significantly linked to acidification were identified with Sanger sequencing, also as previously described, with the exception of the transposon-specific primers. For the first and second rounds of nested PCR, the transposon-specific primers were (5' - GTATCGCCGCTCCCG - 3', and (5' - CATCGCCTTCTATCGCCTTC - 3'), respectively.

\section{Thymol Blue Endpoint Acidity Assay}

Endpoint acidity was measured using the $\mathrm{pH}$ indicator thymol blue (TB, Sigma-Aldrich, St. Louis, MO), which changes from red to yellow below a (https://www.sigmaaldrich.com/US/en/product/sial/114545). The lowest $\mathrm{pH}$ of biolixiviant generated by GoB58 was $2.3^{10}$, thus TB allows for distinguishing strains that lower the $\mathrm{pH}$ below that of the wild type 
biolixiviant. To generate biolixiviant, the condensed collection was pin replicated into new growth plates containing $100 \mu \mathrm{L}$ YPM with $100 \mu \mathrm{g} \mathrm{mL}^{-1}$ kanamycin per well. After two days of growth, an equal volume of $40 \% \mathrm{w} / \mathrm{v}$ glucose was added to the cultures for a final solution of $20 \% \mathrm{w} / \mathrm{v}$ glucose. The amount of glucose needed to lower the $\mathrm{pH}$ below 2.3 via the production of gluconic acid was estimated to be $13 \%$ $\mathrm{w} / \mathrm{v}$, but the higher concentration was used to account for any use of glucose as a carbon source and still maintain an excess amount. Viability tests demonstrated that the bacteria were still viable after two days of culture in such a solution (data not shown).

Bacteria were incubated with glucose for 48 hours to allow acid production to reach completion. Plates were then centrifuged for 3 minutes at $3200 \mathrm{~g}$ (top speed) and $90 \mu \mathrm{L}$ of the biolixiviant supernatant was removed and added to TB at a final concentration of $40 \mu \mathrm{g} \mathrm{mL}^{-1}$. After 1 minute of vortexing, absorbance was measured for each well at $435 \mathrm{~nm}$ and $545 \mathrm{~nm}$ on a Synergy 2 plate reader (Biotek Instruments, Winooski, VT, USA). Because of variation in background absorbance from well to well on each plate, absorbance was measured at these two wavelengths, and their ratio was used as a proxy for $\mathrm{pH}$, which correlates linearly within the range of $\mathrm{pH}$ for the majority of biolixiviants produced by the collection (Fig. S1).

\section{Bromophenol Blue Acidification Rate Screen}

Acidification rate was measured using the $\mathrm{pH}$ indicating dye, Bromophenol Blue (BPB). Knockout collection strains were grown for two days. OD was measured at $590 \mathrm{~nm}$ for each well, then $5 \mu \mathrm{L}$ of culture was transferred to a polystyrene assay plate containing $95 \mu \mathrm{L}$ of $2 \% \mathrm{w} / \mathrm{v}$ glucose and $20 \mu \mathrm{g} \mathrm{mL}^{-1} \mathrm{BPB}$ in deionized water. The initial $\mathrm{pH}$ of the culture is just above 5, and within moments of adding culture to glucose with BPB, the color begins to change rapidly. Assay plates were vortexed for one minute after addition of bacterial culture, then immediately transferred to a plate reader where the change in color was tracked by measuring absorbance at $600 \mathrm{~nm}$ every minute for 6 minutes, resulting in 7 reads. Mean rate $(V)$ and R-squared were calculated by the Gen5 microplate reader and imager software (Biotek Instruments). A plot of all $V$ relative to OD demonstrated that the two are correlated, thus $V$ was normalized to OD for each well (Fig. S3).

\section{Hit Identification in Acidification End Point and Rate Screens}

Once every well had its assigned data point (A435/A545 for TB, and $V / O D$ for BPB), hits were determined by first identifying outliers for each plate. The interquartile range and upper and lower bounds were calculated in Microsoft Excel considering all wells with cultured disruption strains. Any data point that was more than 1.5 times over or under the upper or lower bound, respectively, was considered an outlier. A disruption strain was considered a hit if over half of the wells for that strain (or 1 of 2) were outliers.

\section{Acidification End Point and Rate Quantification with Colorimetric Dyes}

For each assay, knockout strains identified as hits were isolated from the knockout collection into new microplates, along with several blanks per plate, and proxy wild type strains - GoB58 strains with an intergenic transposon insertion that should not affect the acidification phenotype (See next methods section). OD and acidification phenotypes were measured for each proxy WT strain separately to verify that growth and acidification are unaffected in these strains (Fig. S4). 
Acidification phenotypes for the disruption strains (for $n$, see Tables S6C and $\mathbf{D}$ ) were compared to that of proxy WT (TB, $n=144$; BPB, $n=31$ ) with a Student's $t$-test in Microsoft Excel, two-tailed assuming equal variances. A Bonferroni correction was used to determine significance to account for the possibility a comparison is significant by chance alone: a phenotype was considered significant if $p<0.05 / N$, where $N$ is the number of comparisons being made $(N=120$ or $N=242$ for endpoint acidity comparisons with pWT set A or set B, respectively; $N=60$ for rate of acidification comparisons with $\mathrm{pWT}$ ).

\section{Choice of Proxy Wild-type Comparison}

The biolixiviant end point $\mathrm{pH}$ and acidification rate of each $G$. oxydans mutant were compared against a proxy wild-type set of mutants for each phenotype. To account for the presence of a kanamycin cassette in the genome, the proxy wild-type set for each phenotype was constructed of several mutants with the transposon inserted in an intergenic region, that had no growth defect, and no apparent change in phenotype (Fig. S2).

As the efficiency of the E. coli WM3064 to G. oxydans mating was low, construction of the G. oxydans progenitor collection required 18 mating batches. As a result of this, the possibility existed that there might be slight variations in the wild type background from batch to batch.

For the acidificaton rate, these variations did not affect the wild-type behavior across the collection, and a single set of proxy wild-type strains could be used as a comparison with notable disruption strains in the quantification assays. For the end point $\mathrm{pH}$ measurement, two distinct proxy wild-type behaviors arose in the condensed collection. Proxy wild-type set A was used for plates 1 to $76 ; 110$ to 130; and 160 to 185, (Fig. S2A), and proxy wild-type set B was used for plates 77 to 109 and 130 to 159 (Fig. S2B).

Optical density after two days of growth, and endpoint acidity using the TB absorbance ratio (A435/A545) were compared for both wild-type sets (Fig. S2). For wild-type set A, which was used for the BPB quantification assay, acidification rate of individual proxy WT strains was also compared. Pairwise comparisons were all made using the emmeans package in $\mathrm{R}$ with a Tukey $p$-value adjustment (https://github.com/rvlenth/emmeans).

\section{Direct Measurement of Biolixiviant pH}

Bacteria were grown for 48 hours in tubes containing $4 \mathrm{~mL}$ YPM with $100 \mu \mathrm{g} \mathrm{mL}^{-1}$ kanamycin. One tube was left uninoculated as a no-bacteria control. OD was normalized to 1.9 and diluted in half with $40 \%$ glucose for a final $20 \%$ solution in $1.5 \mathrm{~mL}$. Five replicates were created for each strain and controls, and all mixtures were randomly distributed across two deep well plates. $750 \mu \mathrm{L}$ of mixture was transferred from each well to a second set of deep-well plates for bioleaching experiments. All plates were incubated shaking at $800 \mathrm{rpm}$ at room temperature.

After two days, one set of deep-well plates was centrifuged for 10 minutes at $3200 \mathrm{~g}$ (top speed), and the $\mathrm{pH}$ of the supernatant was measured by insertion of a micro-probe to the same depth in each well.

Four standards were used for meter calibration - $\mathrm{pH} \mathrm{1,2,} \mathrm{4,} \mathrm{and} 7$ - and the meter was re-calibrated after every 12 measurements. $\mathrm{pH}$ measurements for each disruption strain $(\mathrm{n}=5)$ were compared with those of proxy WT $(\mathrm{n}=15)$ using a Student's $t$-test in Microsoft Excel, two-tailed, with equal variance. A biolixiviant $\mathrm{pH}$ was considered significantly different if $p<0.05 / \mathrm{N}$, with $\mathrm{N}=22$. 


\section{Direct Measurement of REE Bioleaching}

The second set of deep-well plates was centrifuged for 10 minutes at $3200 \mathrm{~g}$ (top speed), and $500 \mu \mathrm{L}$ of biolixiviant was transferred from each well to a $1.7 \mathrm{~mL}$ Eppendorf tube. $20 \mathrm{mg}(4 \% \mathrm{w} / \mathrm{v})$ of retorted phosphor powder (gift from Idaho National $\mathrm{Lab}^{10}$ ) was added to each tube for bioleaching. Tubes were shaken horizontally for 36 hours at room temperature, then centrifuged to pellet remaining solids. Supernatant with leached REE was filtered through a $0.45 \mu \mathrm{m}$ AcroPrep Advance 96-well Filter Plates (Pall Corporation, Show Low, AZ, USA) by centrifuging at $1500 \times g$ for 5 minutes.

All samples were diluted 1/200 in 2\% trace metal grade nitric acid (Thermo Fisher Scientific) and analyzed by an Agilent 7800 ICP-MS for all REE concentrations ( $m / z$ : Sc, 45; Y, 89; La, 139; Ce, 140; Pr, 141; Nd, 146; Sm, 147; Eu, 153; Gd, 157; Tb, 159; Dy, 163; Ho, 165; Er, 166; Tm, 169; Yb, 172; and Lu, 175) using a rare earth element mix standard (Sigma-Aldrich) and a rhodium in-line internal standard (Sigma-Aldrich, $m / z=103$ ). Quality control was performed by periodic measurement of standards, blanks, and repeat samples. A pWT biolixiviant sample without bioleaching was spiked with $100 \mathrm{ppb}$ REE standard and analyzed for all REE concentrations as a control.

An additional 1/20 dilution in 2\% nitric acid was analyzed for $\delta m g d h$ and $\delta p q q c$ disruption strains, and the no-bacteria control (glucose).

Bioleaching measurements for each disruption strain $(n=5)$ were compared with those of proxy WT $(n=$ $15)$ or glucose $(n=5)$ using a Student's $t$-test in Microsoft Excel, two-tailed, assuming equal variances. Total REE extracted was considered significantly different if $p<0.05 / N$, with $N=12$ for those compared to $\mathrm{pWT}$, and $N=2$ for those compared to glucose. 


\section{End Notes}

\section{Data Availability}

The datasets generated during and analyzed during the current study are available from the corresponding author (B.B.) on reasonable request.

\section{Code Availability}

The Knockout Sudoku software is available at https:/github.com/buzbarstow/kosudoku.

\section{Materials \& Correspondence}

Correspondence and material requests should be addressed to B.B.. Individual strains (up to $\approx 10$ at a time) are available at no charge for academic researchers. We are happy to supply a duplicate of the entire $G$. oxydans knockout collection to academic researchers, but will require reimbursement for materials, supplies and labor costs. Commercial researchers should contact Cornell Technology Licensing for licensing details.

\section{Author Contributions}

Conceptualization, A.M.S. and B.B.; Methodology, A.M.S. and B.B.; Investigation, A.M.S., B.P., S.M., and B.B; Writing - Original Draft, A.M.S. and B.B.; Writing - Review \& Editing, A.M.S., B.P., S.M., M.R., M.W., E.G., and B.B.; Funding Acquisition, A.M.S., E.G., M.W., and B.B.; Resources, M.R., E.G., and B.B.; Supervision, M.R. and B.B.; Data Curation, A.M.S. and B.B.; Visualization, A.M.S. and B.B.; Formal Analysis, A.M.S. and S.M.

\section{Acknowledgements}

We thank D. Reed and Y. Fujita at Idaho National Lab for advice and for gift of rare containing retorted phosphor powder. A.M.S. was supported by a Cornell Energy Systems Institute Postdoctoral Fellowship, and a Small Grant from the Cornell Atkinson Center for Sustainability. This work was supported by Cornell University startup funds, an Academic Venture Fund award from the Atkinson Center for Sustainability at Cornell University, a Career Award at the Scientific Interface from the Burroughs Welcome Fund to B.B., and by ARPA-E award DE-AR0001341 to B.B, E.G., and M.W..

\section{Competing Interests}

The authors are pursuing patent protection for engineered organisms using knowledge gathered in this work (US provisional application 63/220,475). 


\section{Figures}

A. G. oxydans B58 Genome Annotation Statistics

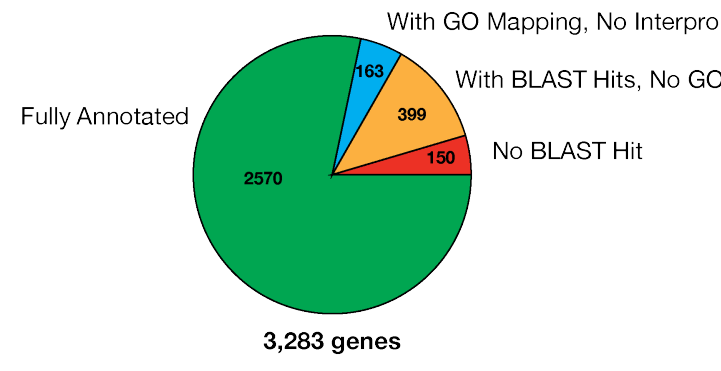

\section{GO enrichment for Non-disrupted Genes}

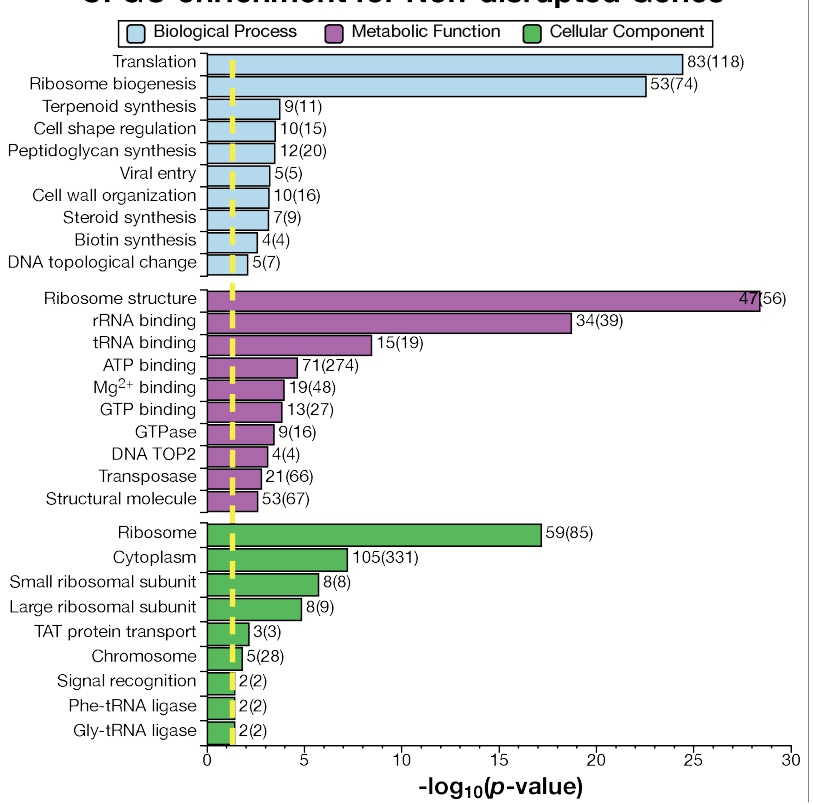

\section{B. Saturation of Possible Disruption Mutants}

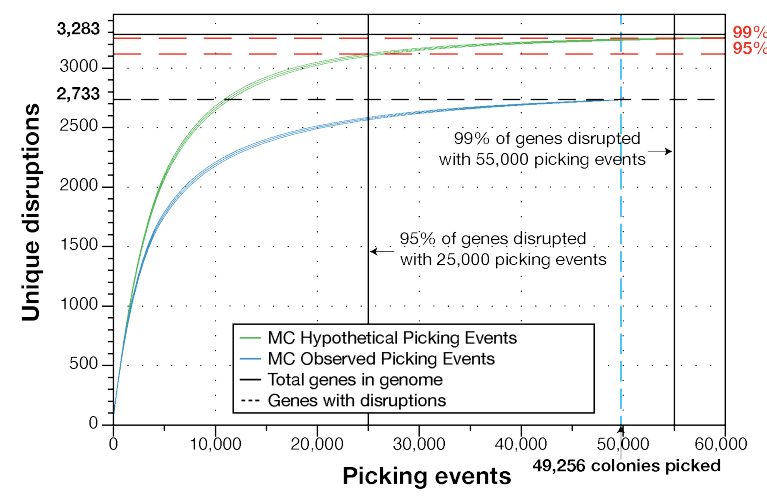

D. G. oxydans B58 Knockout Collection Statistics

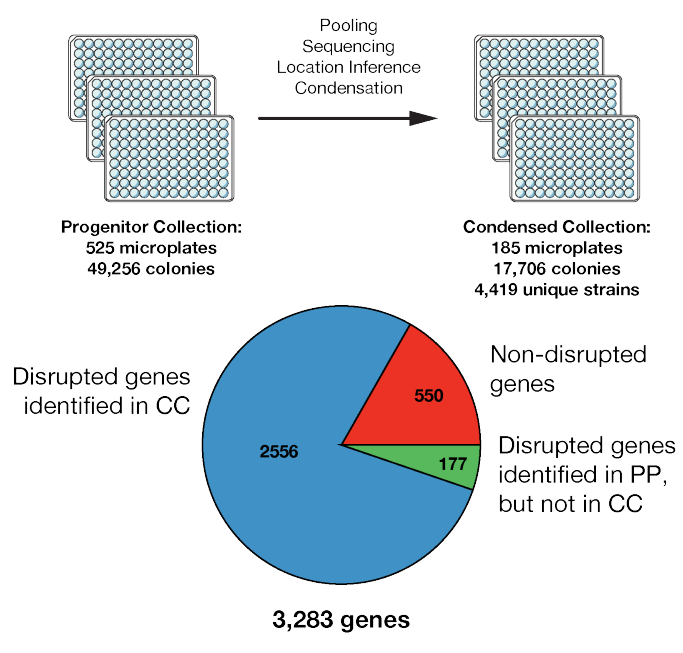

Figure 1. Knockout Sudoku was used to curate a saturating coverage transposon insertion mutant collection for Gluconobacter oxydans B58. (A) The G. oxydans B58 genome contains 3,283 genes. 2,570 genes were fully annotated with a BLAST hit, Interpro ID, and gene ontology (GO) group. An additional 163 genes have an annotation and GO group, but lack an Interpro ID, 399 only retrieved a BLAST hit, but no GO group, and 150 were unable to be assigned any annotation. (B) A Monte Carlo (MC) estimate of the number of genes represented by at least one mutant as a function of the number of mutants collected demonstrated that picking 25,000 mutants would yield at least one disruption for 95\% of genes, while picking 50,000 mutants would yield at least one disruption for $99 \%$ of genes. In total, we picked 49,256 single-gene disruption mutants and located at least one disruption for 2,733 genes. A Monte Carlo simulation of picking with random drawing from the sequenced progenitor collection (PC) without replacements demonstrates that the genome coverage was truly saturated. The center of each curve is the mean value of the unique gene disruption count from 1,000 simulations while the upper and lower part of each curve represent two standard deviations around this mean. (C) A Fisher's Exact Test for gene ontology enrichment among the non-disrupted (putatively essential) genes revealed significant enrichment ( $p<0.05$, yellow line) of genes involved in translation and other ribosome-related functions. (D) The curated condensed collection (CC) contains 17,706 isolated colonies across 185 plates. High-throughput sequencing of the CC confirmed the 
bioRxiv preprint doi: https://doi.org/10.1101/2021.07.11.451920; this version posted July 12, 2021. The copyright holder for this preprint (which was not certified by peer review) is the author/funder. All rights reserved. No reuse allowed without permission.

Schmitz et al., G. oxydans Knockout Collection Finds Improved Rare Earth Element Extraction

location for 4,419 unique disruption strains, representing disruptions in 2,556 genes. 177 genes located in the PC were not located in the CC. No disruption mutant was detected in 550 genes. 


\section{A. TB Screen Finds Knockout of Gene Involved in Phosphate Transport Reduces Final Acidity}

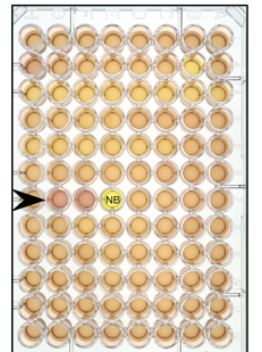

CC Plate 65

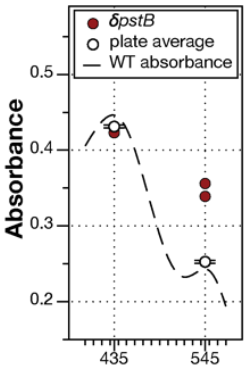

Wavelength

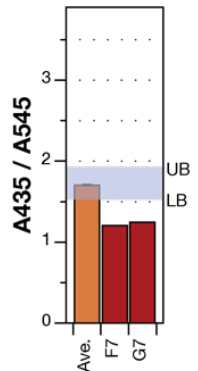

סpstB

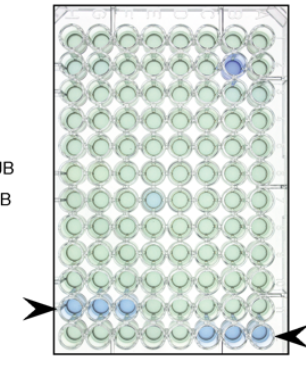

CC Plate 162
B. BPB Screen Finds Knockout of Gene Likely Involved in PQQ Synthesis Slows Acidification Rate

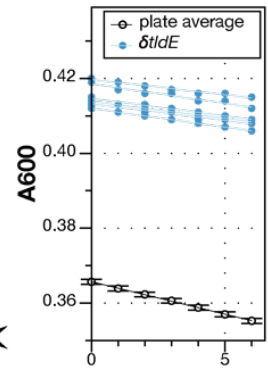

Time (minutes)

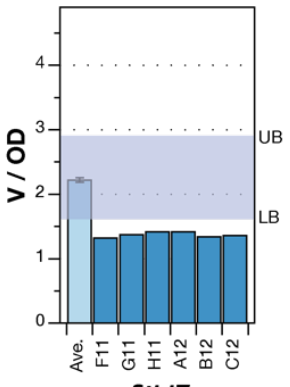

$\delta$ tIdE

C. Work flow for identifying comprehensive set of genes underlying acidification

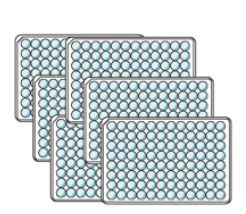

G. oxydans B58 Knockout Collection (185 microplates)

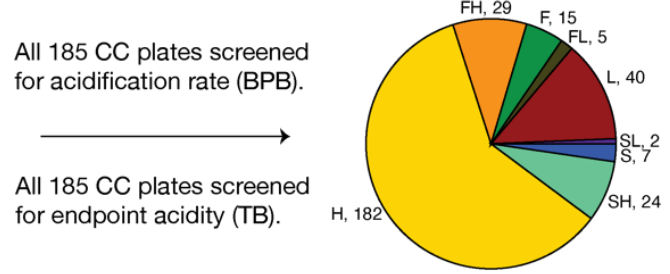

304 Total Screen Hits

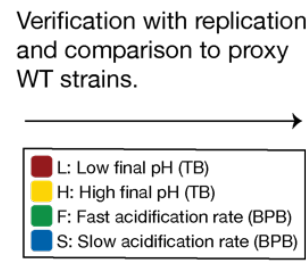

F: Fast acidification rate (BPB)
S: Slow acidification rate (BPB)

165 Total Verified Hits

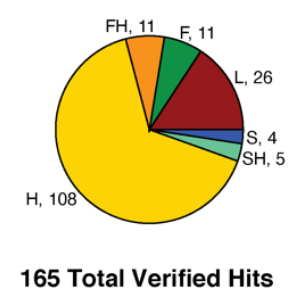

D. 25 Biggest Reductions and 50 Biggest Increases in Biolixiviant Acidity

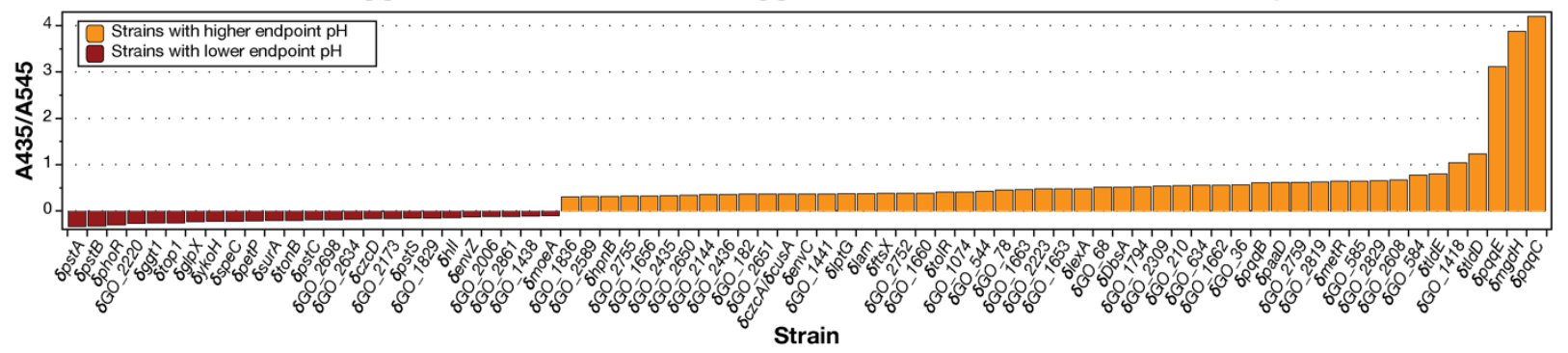

E. Most Significant Changes in Acidification Rate

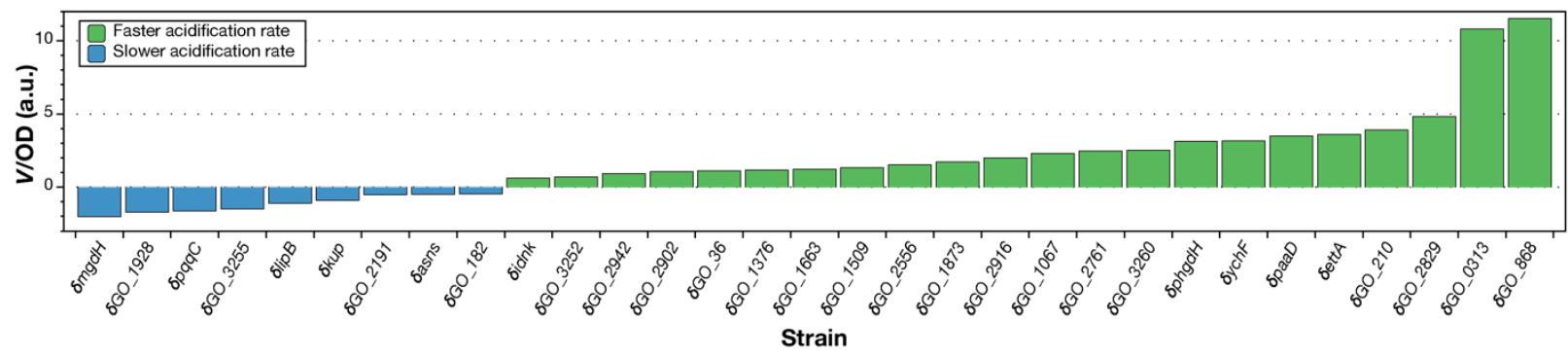

Figure 2. High-throughput $\mathrm{pH}$ screens of the G. oxydans whole genome knockout collection were used to identify genes that control REE bioleaching. (A) Thymol blue (TB) was used to measure the endpoint acidity of biolixiviant produced by each well of the condensed collection. The ratio of TB absorbance (A) at 435 and $545 \mathrm{~nm}$ is linearly related to $\mathrm{pH}$ between 2 and 3.4 (Fig S1). CC plate 65 contains biolixiviant produced by $\delta p s t B$ strain in wells F7 and G7 (arrowhead), whose absorbance at $435 \mathrm{~nm}$ and $545 \mathrm{~nm}$ is shown, along with the average absorbance of all wells on the plate. The dashed line represents a typical absorbance spectrum for WT-produced biolixiviant. The A435/A545 ratio for these two wells compared with the average ratio of the plate is well below the lower bound (LB) for the plate, indicating that $\delta p s t B$ produces a much more acidic biolixiviant than the average strain. (B) Bromophenol blue (BPB) was used 
to measure rate of change in $\mathrm{pH}$ at the onset of glucose conversion to organic acids. Rate was measured over a six minute period within five minutes of adding bacteria to a glucose and BPB solution. Condensed collection (CC) plate 162 contains the $\delta$ tldE strain in wells F11 - C12 (arrowheads), whose changes in absorbance over time are graphed along with the average for that plate. A comparison of the normalized rate over OD for each well versus the plate average shows how $V / O D$ for these wells was below the lower bound for CC plate 162. (C) All 185 plates of the CC were screened for acidification using the TB and BPB assays. Hits from both screens were verified in comparison with proxy WT strains. In total, 176 disruption strains were shown to significantly contribute to acidification by $t$-test with a Bonferroni-corrected alpha ( $\alpha=0.05$ / \# of comparisons). (D) The 25 largest reductions in biolixiviant $\mathrm{pH}$, and 50 largest increases in biolixiviant pH (Table S6E). (E) All significant changes in acidification rate (Table S6F). 
bioRxiv preprint doi: https://doi.org/10.1101/2021.07.11.451920; this version posted July 12, 2021. The copyright holder for this preprint (which was not certified by peer review) is the author/funder. All rights reserved. No reuse allowed without permission.

\section{Enriched Gene Ontologies that Change Final pH}

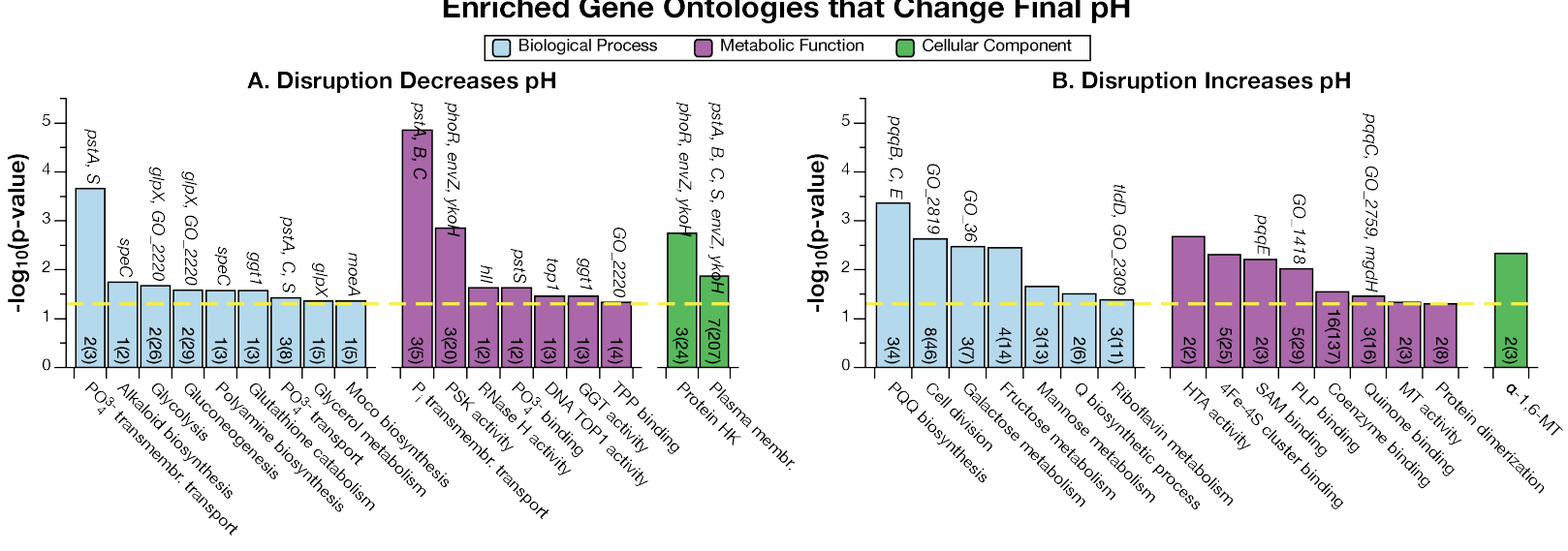

Enriched Gene Ontologies that Change Initial Acidification Rate

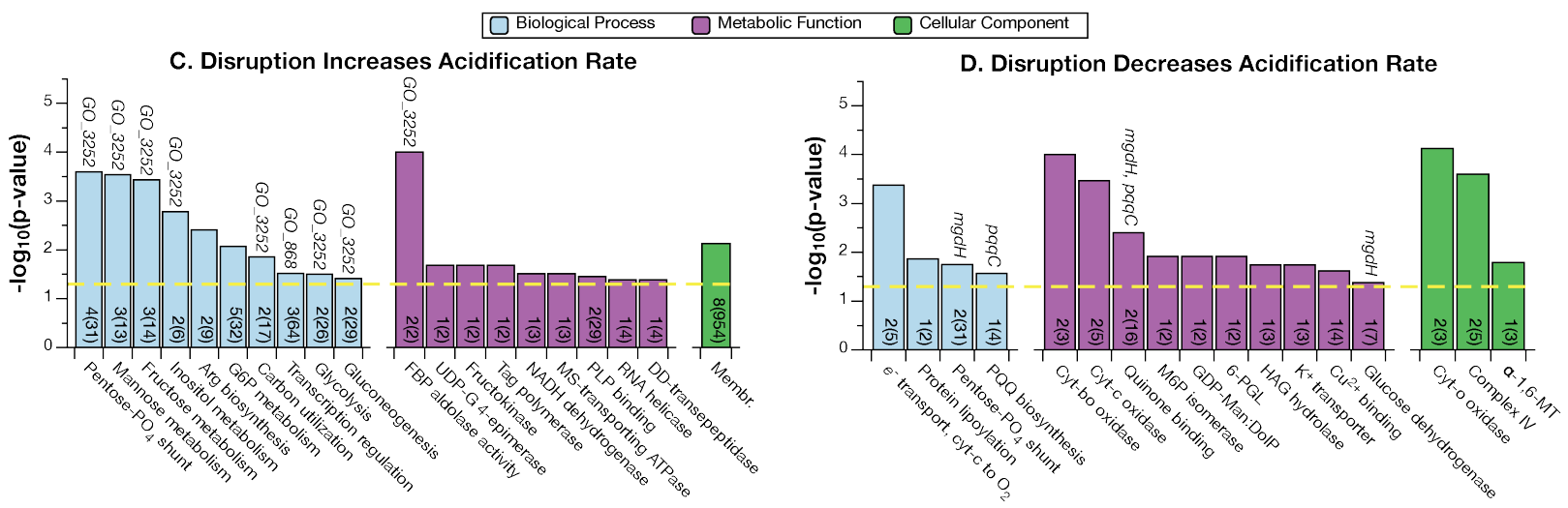



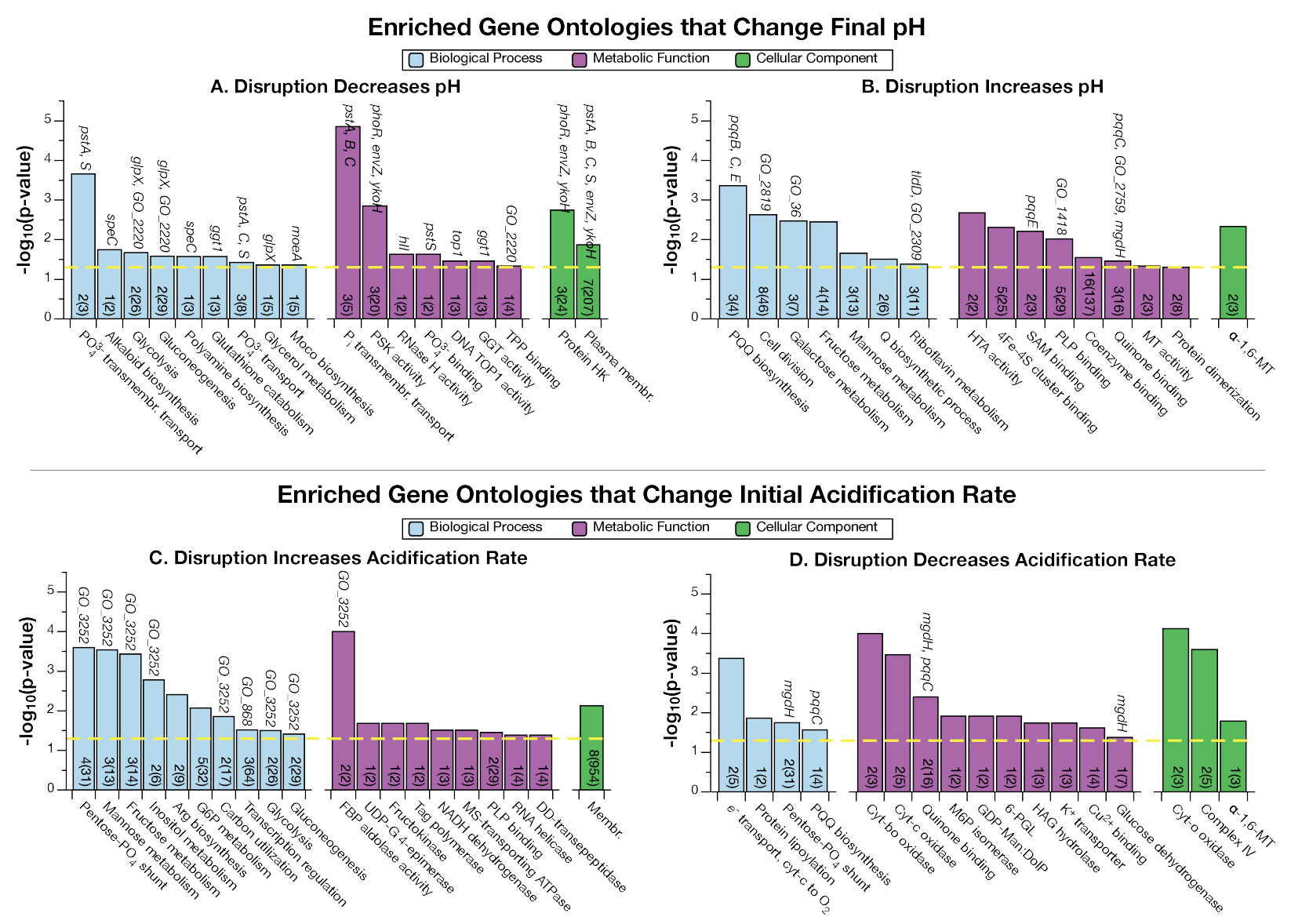

Figure 3. Genes involved in phosphate signaling, carbohydrate metabolism and PQQ synthesis were significantly overrepresented in the significant hits from high-throughput screens of acidification by $G$. oxydans. Fisher's Exact Test was used to test for gene ontology enrichment ( $p<0.05$, yellow dashed line). Numbers at base of bars are how many genes from the significant hits are from that gene ontology (GO), out of the total in the genome (in parentheses). Genes selected for further analysis of endpoint $\mathrm{pH}$ and bioleaching (Fig. 4) that contribute to an enriched GO are listed above the bars. (A and B) Enriched GO among genes that decrease and increase end point $\mathrm{pH}$. (C and D) Enriched GO among genes that increase and decrease initial acidification rate. Abbreviations: FBP: fructose-bisphosphate; GDP-Man:DolP: dolichyl-phosphate beta-D-mannosyltransferase; GGT: glutathione hydrolase; G6P: glucose 6-phosphate; HTA: homoserine O-acetyltransferase; DD-transepeptidase: D-Ala-D-Ala carboxypeptidase; HAG: hydroxyacylglutathione; Membr: membraneMoco: Mo-molybdopterin cofactor; MS: monosaccharide; MT: mannosyltransferase;M6P: mannose-6-phosphate; $\mathrm{P}_{\mathrm{i}}$ : inorganic phosphate;PLP: pyridoxal phosphate;PQQ: pyrroloquinoline quinone;PSK: phosphorelay sensor kinase; Q: queuosine; RNase H: DNA-RNA hybrid ribonuclease;SAM: S-adenosyl-L-methionine; TPP: thiamine pyrophosphate; TOP1: topoisomerase type 1; HK: histidine kinase; UDP-G: uracil-diphosphate glucose; 6-PGL: 6phosphogluconolactonase. 
bioRxiv preprint doi: https://doi.org/10.1101/2021.07.11.451920; this version posted July 12, 2021. The copyright holder for this preprint (which was not certified by peer review) is the author/funder. All rights reserved. No reuse allowed without permission.

Schmitz et al., G. oxydans Knockout Collection Finds Improved Rare Earth Element Extraction
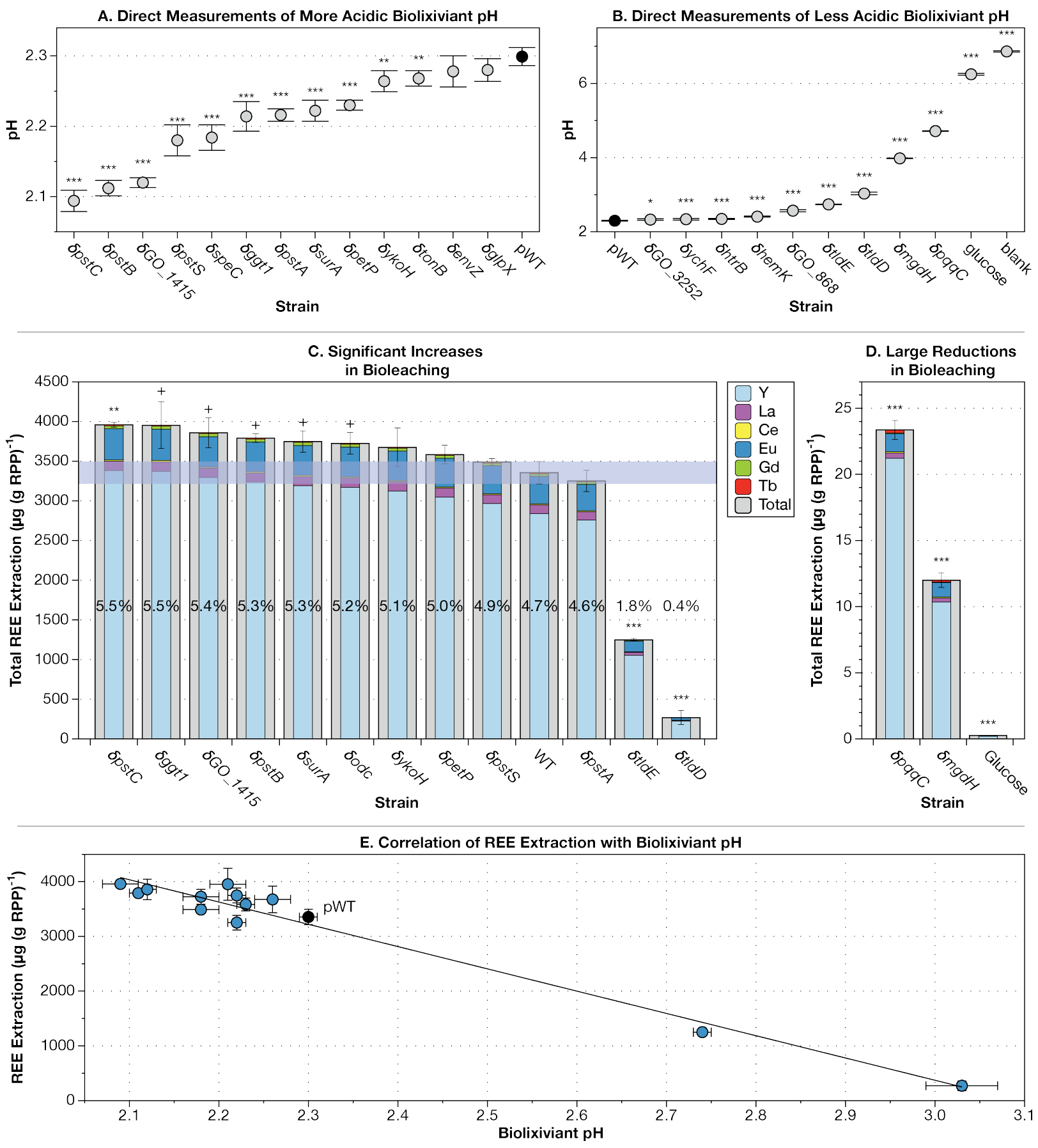

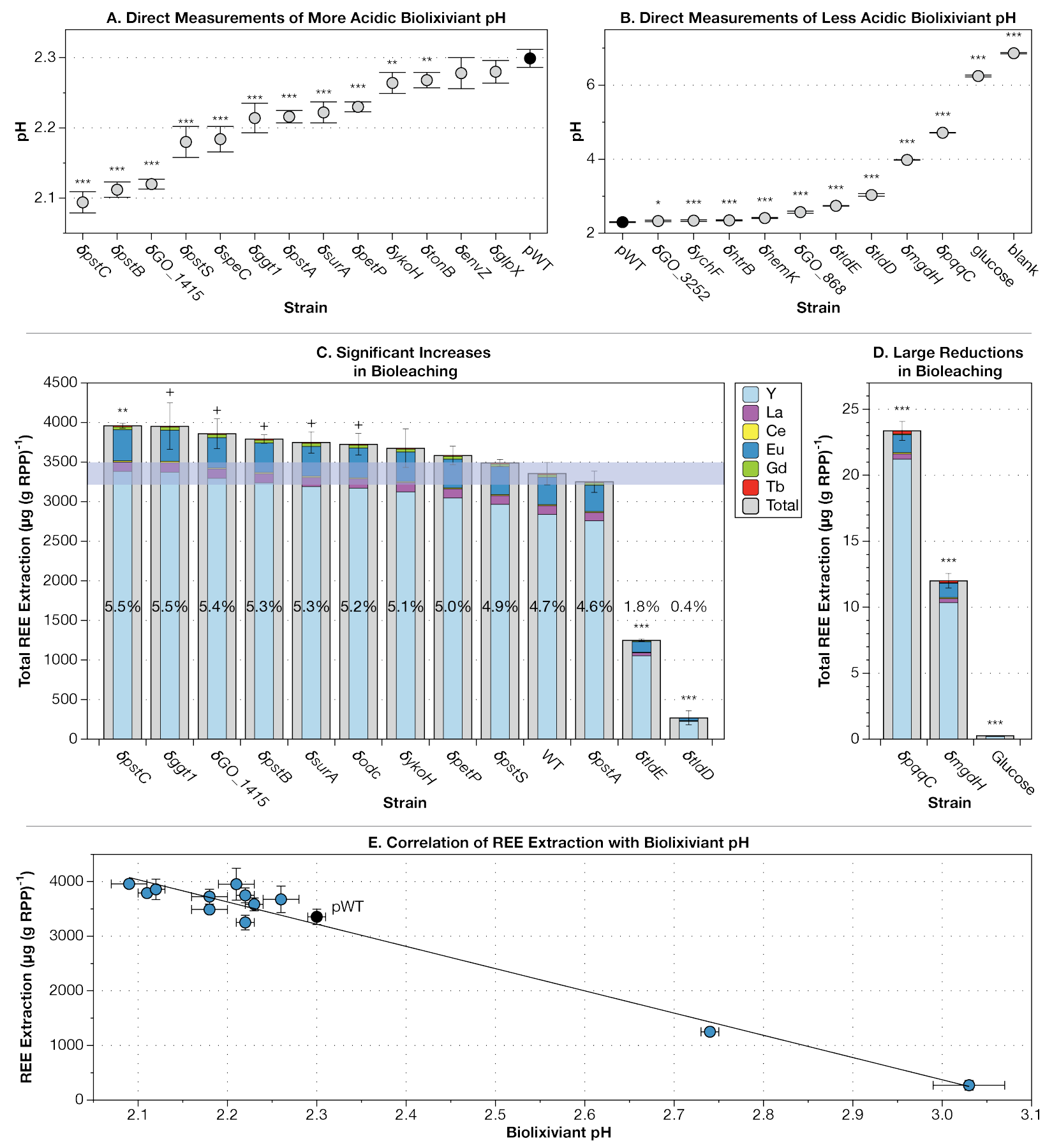

Figure 4. Increased acidification strains of G. oxydans B58 are able to increase rare earth extraction from retorted phosphor powder (RPP). (A and B) A subset of 20 disruption strains were tested for acidification with direct $\mathrm{pH}$ measurement. $\mathrm{pH}$ measurements significantly different from $\mathrm{pWT}$ (black circle) are labeled with asterisks: $*, p<0.05 ; * *, p<0.01 ; * * *, p<0.001(\mathrm{n}=5, \mathrm{df}=18)$. Error bars represent standard deviation. (C and D) Ten disruption strains with the lowest final biolixiviant $\mathrm{pH}$ and four with the highest were tested for RPP bioleaching capabilities. Outer gray bars represent total REE extracted. Inner multicolored bars represent fractional contributions of each REE. Error bars represent standard error for total REE extracted. Percentages are total REE extraction efficiency (based on previously published REE 
amounts in the RPP [Reed2016a]). (C) Using a two-tailed $t$-test between each mutant and pWT demonstrated eight strains were significantly better or worse at bioleaching total $\operatorname{REE~}(+, p<0.05 ; \mathrm{n}=5$, $\mathrm{df}=18$ ). With a Bonferonni correction, only one was significantly better $(* *, p<0.01 / 12)$, but two of the higher $\mathrm{pH}$ biolixiviants that extracted detectable REE were significantly attenuated in bioleaching capability (***, $p<0.001 / 12$ ). (D) Disruption mutants for $m g d h$ and $p q q C$ are only able to extract less than $1 \%$ of the REE that wild-type $G$. oxydans can, but still extract significantly more REE than glucose alone when measured at a lesser dilution (***, $p<0.001 / 2$ ). (E) Total REE extraction linearly correlates with $\mathrm{pH}$. Error bars represent standard deviation for $\mathrm{pH}$ and standard error for total REE extracted. 


\section{Bibliography}

1 Zepf, V. in Rare Earths Industry Ch. 1, 3-17 (2015).

2 Brisson, V. L., Zhuang, W.-Q. \& Alvarez-Cohen, L. Bioleaching of rare earth elements from monazite sand. Biotechnology and Bioengineering 113, 339-348, doi:10.1002/bit.25823 (2016).

3 Cockell, C. S. et al. Space station biomining experiment demonstrates rare earth element extraction in microgravity and Mars gravity. Nature Communications 11, 5523, doi:10.1038/s41467-020-19276-w (2020).

4 Rasoulnia, P., Barthen, R. \& Lakaniemi, A.-M. A critical review of bioleaching of rare earth elements: The mechanisms and effect of process parameters. Crit Rev Env Sci Tec 51, 1-50, doi:10.1080/10643389.2020.1727718 (2020).

5 Johnson, D. B. Biomining - biotechnologies for extracting and recovering metals from ores and waste materials. Current Opinion in Biotechnology 30, 24-31, doi:10.1016/j.copbio.2014.04.008 (2014).

6 Brierley, C. L. in Innovative Process Development in Metallurgical Industry, Concept to Commission Ch. 6, 109-135 (2016).

7 Merritt, R. R. High temperature methods for processing monazite: I. Reaction with calcium chloride and calcium carbonate. J Less Common Metals 166, 197-210, doi:10.1016/00225088(90)90001-z (1990).

8 Thompson, V. S. et al. Techno-economic and Life Cycle Analysis for Bioleaching Rare-Earth Elements from Waste Materials. ACS Sustainable Chemistry \& Engineering 6, 1602-1609, doi:10.1021/acssuschemeng.7b02771 (2018).

9 Jin, H. et al. Sustainable Bioleaching of Rare Earth Elements from Industrial Waste Materials Using Agricultural Wastes. ACS Sustainable Chemistry \& Engineering 7, 15311-15319, doi:10.1021/acssuschemeng.9b02584 (2019).

10 Reed, D. W., Fujita, Y., Daubaras, D. L., Jiao, Y. \& Thompson, V. S. Bioleaching of rare earth elements from waste phosphors and cracking catalysts. Hydrometallurgy 166, 34--40, doi:10.1016/j.hydromet.2016.08.006 (2016).

11 Bauer, D. et al. Critical Materials Strategy. (U.S. Department of Energy, 2011).

12 Grasso, V. B. Rare earth elements in national defense: Background, oversight issues, and options for congress. Report No. R41744, (Congressional Research Service, Washington, DC, 2013). 
13 Humphries, M. Rare earth elements: The global supply chain. Report No. R41347, (Congressional Research Service, Washington, DC, 2013).

14 Dent, P. C. Rare earth elements and permanent magnets. Journal of Applied Physics 111, 07A721, doi:10.1063/1.3676616 (2012).

15 Nazarov, M. \& Noh, D. New Generation of Europium- and Terbium-Activated Phosphors. (Pan Stanford Publishing, 2011).

16 Müller, T. \& Friedrich, B. Development of a recycling process for nickel-metal hydride batteries. J Power Sources 158, 1498-1509, doi:10.1016/j.jpowsour.2005.10.046 (2006).

17 Schubert, E. F. \& Kim, J. K. Solid-State Light Sources Getting Smart. Science 308, 1274-1278, doi:10.1126/science.1108712(2005).

18 Norman, A. F., Prangnell, P. B. \& McEwen, R. S. The solidification behaviour of dilute aluminium-scandium alloys. Acta Mater 46, 5715-5732, doi:10.1016/s1359-6454(98)00257-2 (1998).

19 Adesina, O., Anzai, I. A., Avalos, J. L. \& Barstow, B. Embracing Biological Solutions to the Sustainable Energy Challenge. Chem 2, 20-51, doi:10.1016/j.chempr.2016.12.009 (2017).

20 Global Rare Earth Materials Market, Forecast to 2025. (Frost \& Sullivan, 2019).

21 Annual Energy Outlook 2020, with projections to 2050. (U.S. Energy Information Administration, Office of Energy Analysis, U.S. Department of Energy, Washington, DC, 2020).

22 Voncken, J. H. L. The Rare Earth Elements, An Introduction. Springerbriefs Earth Sci, doi:10.1007/978-3-319-26809-5 (2016).

23 Scheyder, E. China Set to Control Rare Earth Supply for Years Due to Processing Dominance, $<$ https://www.reuters.com/article/us-china-usa-rareearth-refining/china-set-to-control-rare-earthsupply-for-years-due-to-processing-dominance-idUSKCN1T004J $>$ (2019).

24 Mining the Future: How China is set to dominate the next Industrial Revolution. (Foreign Policy, 2019).

25 Bonificio, W. D. \& Clarke, D. R. Rare-Earth Separation Using Bacteria. Environmental Science \& Technology Letters 3, 180-184, doi:10.1021/acs.estlett.6b00064 (2016).

26 Park, D. M. et al. Bioadsorption of Rare Earth Elements through Cell Surface Display of Lanthanide Binding Tags. Environmental Science and Technology 50, 2735-2742, doi:10.1021/acs.est.5b06129 (2016). 
27 Jin, H. et al. Techno-economic Assessment for Integrating Biosorption into Rare Earth Recovery Process. ACS Sustainable Chemistry and Engineering 5, 10148-10155, doi:10.1021/acssuschemeng.7b02147 (2017).

28 Valdés, J. et al. Acidithiobacillus ferrooxidans metabolism: from genome sequence to industrial applications. BMC Genomics 9, 597, doi:10.1186/1471-2164-9-597 (2008).

29 Gentina, J. C. \& Acevedo, F. Copper Bioleaching in Chile. Mineral-basel 6, 23, doi:10.3390/min6010023 (2016).

30 Peelman, S., Sun, Z. H. I., Sietsma, J. \& Yang, Y. in ERES2014: 1st European Rare Earth Resources Conference.

31 Capeness, M. J. \& Horsfall, L. E. Synthetic biology approaches towards the recycling of metals from the environment. Biochemical Society Transactions 48, 1367-1378, doi:10.1042/bst20190837 (2020).

32 Schleyer, U., Bringer-Meyer, S. \& Sahm, H. An easy cloning and expression vector system for Gluconobacter oxydans. Int J Food Microbiol 125, 91-95, doi:10.1016/j.ijfoodmicro.2007.04.016 (2008).

33 Kallnik, V., Meyer, M., Deppenmeier, U. \& Schweiger, P. Construction of expression vectors for protein production in Gluconobacter oxydans. Journal of Biotechnology 150, 460-465, doi:10.1016/j.jbiotec.2010.10.069 (2010).

34 Kostner, D., Peters, B., Mientus, M., Liebl, W. \& Ehrenreich, A. Importance of codB for new codA-based markerless gene deletion in Gluconobacter strains. Applied Microbiology and Biotechnology 97, 8341-8349, doi:10.1007/s00253-013-5164-7 (2013).

35 Fricke, P. M. et al. A tunable 1-arabinose-inducible expression plasmid for the acetic acid bacterium Gluconobacter oxydans. Applied Microbiology and Biotechnology 104, 9267-9282, doi:10.1007/s00253-020-10905-4 (2020).

36 Qin, Z. et al. Repurposing the Endogenous Type I-E CRISPR/Cas System for Gene Repression in Gluconobacter oxydans WSH-003. ACS Synthetic Biology 10, 84-93, doi:10.1021/acssynbio.0c00456 (2021).

37 Chen, Y. et al. Identification of Gradient Promoters of Gluconobacter oxydans and Their Applications in the Biosynthesis of 2-Keto-L-Gulonic Acid. Frontiers Bioeng Biotechnology 9, 673844, doi:10.3389/fbioe.2021.673844 (2021). 
38 Gupta, A., Verma, V. \& Qazi, G. N. Transposon induced mutation in Gluconobacter oxydans with special reference to its direct-glucose oxidation metabolism. FEMS Microbiology Letters 147, 181-188, doi:10.1111/j.1574-6968.1997.tb10239.x (1997).

39 Baym, M., Shaket, L., Anzai, I. A., Adesina, O. \& Barstow, B. Rapid construction of a wholegenome transposon insertion collection for Shewanella oneidensis by Knockout Sudoku. Nature Communications 7, 13270, doi:10.1038/ncomms13270 (2016).

40 Anzai, I. A., Shaket, L., Adesina, O., Baym, M. \& Barstow, B. Rapid curation of gene disruption collections using Knockout Sudoku. Nature Protocols 12, 2110-2137, doi:10.1038/nprot.2017.073 (2017).

41 Krajewski, V. et al. Metabolic Engineering of Gluconobacter oxydans for Improved Growth Rate and Growth Yield on Glucose by Elimination of Gluconate Formation ${ }^{\nabla}$. Applied and Environmental Microbiology 76, 4369-4376, doi:10.1128/aem.03022-09 (2010).

42 Shin, D., Kim, J., Kim, B.-s., Jeong, J. \& Lee, J.-c. Use of Phosphate Solubilizing Bacteria to Leach Rare Earth Elements from Monazite-Bearing Ore. Mineral-basel 5, 189-202, doi:10.3390/min5020189 (2015).

43 Rodríguez, H. \& Fraga, R. Phosphate solubilizing bacteria and their role in plant growth promotion. Biotechnol Adv 17, 319-339, doi:10.1016/s0734-9750(99)00014-2 (1999).

44 Hsieh, Y.-J. \& Wanner, B. L. Global regulation by the seven-component Pi signaling system. Curr Opin Microbiol 13, 198-203, doi:10.1016/j.mib.2010.01.014 (2010).

45 Hölscher, T. \& Görisch, H. Knockout and Overexpression of Pyrroloquinoline Quinone Biosynthetic Genes in Gluconobacter oxydans $621 \mathrm{H}^{\nabla}$. Journal of Bacteriology 188, 7668-7676, doi:10.1128/jb.01009-06 (2006).

46 Ghilarov, D. et al. The Origins of Specificity in the Microcin-Processing Protease TldD/E. Structure 25, 1549-1561.e1545, doi:10.1016/j.str.2017.08.006 (2017).

47 Martins, A. M. et al. A two-component protease in Methylorubrum extorquens with high activity toward the peptide precursor of the redox cofactor pyrroloquinoline quinone. Journal of Biological Chemistry 294, 15025-15036, doi:10.1074/jbc.ra119.009684 (2019).

48 Muynck, C. D. et al. The Genus Gluconobacter Oxydans: Comprehensive Overview of Biochemistry and Biotechnological Applications. Crit Rev Biotechnol 27, 147-171, doi:10.1080/07388550701503584 (2008). 
49 Matsutani, M. \& Yakushi, T. Pyrroloquinoline quinone-dependent dehydrogenases of acetic acid bacteria. Applied Microbiology and Biotechnology 102, 9531-9540, doi:10.1007/s00253-0189360-3 (2018).

50 Liu, D., Ke, X., Hu, Z.-C. \& Zheng, Y.-G. Improvement of pyrroloquinoline quinone-dependent d-sorbitol dehydrogenase activity from Gluconobacter oxydans via expression of Vitreoscilla hemoglobin and regulation of dissolved oxygen tension for the biosynthesis of 6-(Nhydroxyethyl)-amino-6-deoxy- $\alpha$-1-sorbofuranose. J Biosci Bioeng 131, 518-524, doi:10.1016/j.jbiosc.2020.12.013 (2021).

51 Liu, D., Ke, X., Hu, Z.-C. \& Zheng, Y.-G. Combinational expression of D-sorbitol dehydrogenase and pyrroloquinoline quinone increases 6-(N-hydroxyethyl)-amino-6-deoxy- $\alpha$-Lsorbofuranose production by Gluconobacter oxydans through cofactor manipulation. Enzyme Microb Tech 141, 109670, doi:10.1016/j.enzmictec.2020.109670 (2020).

52 Wang, P. et al. Overexpression of pyrroloquinoline quinone biosynthetic genes affects 1-sorbose production in Gluconobacter oxydans WSH-003. Biochem Eng J 112, 70-77, doi:10.1016/j.bej.2016.04.011 (2016).

53 Yuan, J., Wu, M., Lin, J. \& Yang, L. Combinatorial metabolic engineering of industrial Gluconobacter oxydans DSM2343 for boosting 5-keto-D-gluconic acid accumulation. Bmc Biotechnol 16, 42, doi:10.1186/s12896-016-0272-y (2016).

54 Misra, H. S., Rajpurohit, Y. S. \& Khairnar, N. P. Pyrroloquinoline-quinone and its versatile roles in biological processes. J Biosciences 37, 313-325, doi:10.1007/s12038-012-9195-5 (2012).

55 Bolger, A. M., Lohse, M. \& Usadel, B. Trimmomatic: a flexible trimmer for Illumina sequence data. Bioinformatics 30, 2114-2120, doi:10.1093/bioinformatics/btu170 (2014).

56 Bankevich, A. et al. SPAdes: A New Genome Assembly Algorithm and Its Applications to Single-Cell Sequencing. J Comput Biol 19, 455-477, doi:10.1089/cmb.2012.0021 (2012).

57 Gurevich, A., Saveliev, V., Vyahhi, N. \& Tesler, G. QUAST: quality assessment tool for genome assemblies. Bioinformatics 29, 1072-1075, doi:10.1093/bioinformatics/btt086 (2013).

58 Seppey, M., Manni, M. \& Zdobnov, E. M. Gene Prediction, Methods and Protocols. Methods Mol Biology 1962, 227-245, doi:10.1007/978-1-4939-9173-0_14 (2019).

59 Brettin, T. et al. RASTtk: A modular and extensible implementation of the RAST algorithm for building custom annotation pipelines and annotating batches of genomes. Scientific Reports 5, 8365, doi:10.1038/srep08365 (2015). 
60 Overbeek, R. et al. The SEED and the Rapid Annotation of microbial genomes using Subsystems Technology (RAST). Nucleic Acids Research 42, D206-D214, doi:10.1093/nar/gkt1226 (2014).

61 Aziz, R. K. et al. The RAST Server: Rapid Annotations using Subsystems Technology. BMC Genomics 9, 75, doi:10.1186/1471-2164-9-75 (2008).

62 Buchfink, B., Reuter, K. \& Drost, H.-G. Sensitive protein alignments at tree-of-life scale using DIAMOND. Nat Methods 18, 366-368, doi:10.1038/s41592-021-01101-x (2021).

63 Jones, P. et al. InterProScan 5: genome-scale protein function classification. Bioinformatics 30, 1236-1240, doi:10.1093/bioinformatics/btu031 (2014).

64 Götz, S. et al. High-throughput functional annotation and data mining with the Blast2GO suite. Nucleic Acids Research 36, 3420-3435, doi:10.1093/nar/gkn176 (2008).

65 Adrian, A. \& Jörg, R. Gene Set Enrichment Analysis with topGO, $<$ http://compdiag.molgen.mpg.de/ngfn/docs/2007/sep/topGO_Exercises.pdf $>$ (2007). 